\title{
AS FLORES ESTÃO BROTANDO: ATENDIMENTO INFANTIL EM CONSULTAS TERAPÊUTICAS
}

\author{
Claudia Mazzer Rodrigues* \\ Fernanda Kimie Tavares Mishima-Gomes**
}

\section{Resumo}

As consultas terapêuticas são uma modalidade de atendimento psicoterápico que representa nova possibilidade de intervenção psicológica voltada para a escuta, para a prática e para a flexibilidade clínicas advindas da teoria do amadurecimento humano. Tal modalidade possibilita sustentação emocional para que o paciente possa retomar sua continuidade de ser e seu processo de amadurecimento emocional. Apresenta-se o caso de uma menina de oito anos de idade, atendida em consultas terapêuticas na clínica-escola de uma universidade pública. A procura pelo atendimento foi realizada pela mãe, que relatou como principais queixas: humor deprimido, dores no peito e temperamento difícil. O manejo clínico e as experiências constitutivas do si mesmo por meio do brincar compartilhado possibilitaram à criança a expressáo do gesto espontâneo, da criatividade e de uma maior confiança na própria capacidade.

Palavras-chave: brincar; crianças; criatividade; consultas terapêuticas; desenvolvimento emocional; Winnicott.

\footnotetext{
Abstract

THE FLOWERS ARE BLOOMING: CHILD CARE IN THERAPEUTIC CONSULTATIONS

Therapeutic consultations are a modality of therapeutic assessment with possibility of psychological evaluation and intervention by means of practical, clinical flexibility and psychoanalysis of listening, in accordance with theory of

* Programa de Pós-Graduação em Psicologia da Universidade de São Paulo. Ribeirão Preto, São Paulo, Brasil. E-mail: claudiamr@usp.br.

** Departamento de Psicologia da Universidade de São Paulo. Ribeirão Preto, São Paulo, Brasil. E-mail: fktmishima@ffclrp.usp.br.
} 
human's maturity. This therapeutic modality provides an emotional support so the patient can retake his continuity of being and his emotional maturation process. This study presents eight year-old girl's case, in therapeutic consultations in a public university's school clinic. The demand for care was done by her mother who reported complaints such as depressed mood, chest pains and difficult temperament. The clinical handling and the experiences that constitutes itself through the shared play allowed the expression of child's spontaneous gesture, creativity and confidence in his ability.

Keywords: playing; children; creativity; therapeutic consultations; emotional development; Winnicott.

\section{Resumen}

LAS FLORES ESTÁN BROTANDO: ATENCIÓN PSICOLÓGICA DE LOS NIÑOS EN CONSULTAS TERAPÉUTICAS

Las consultas terapéuticas son una modalidad de psicoterapia que representa una nueva posibilidad de intervención psicológica centrado en la escucha, en la práctica y en la flexibilidad clinicas derivadas de la teoría de la maduración humana. Esta modalidad proporciona apoyo emocional para que el paciente pueda reanudar su continuidad existencial y su proceso de maduración emocional. Se presenta el caso de una niña de ocho años de edad, recibida en consultas terapéuticas en la clínica-escuela en una universidad pública. La demanda del servicio ha estado en manos de su madre, quien reportó las siguientes quejas: estado de ánimo depresivo, dolor en el pecho y temperamento dificil. La gestión clínica y las experiencias constitutivas del yo a través del juego compartido han permitido la expresión del gesto espontáneo, la creatividad y una mayor confianza en su capacidad.

Palabras clave: juego; niños; creatividad; consultas terapéuticas; desarrollo emocional; Winnicott.

\section{A teoria do amadurecimento humano}

A teoria do amadurecimento humano, desenvolvida pelo pediatra e psicanalista inglês Donald W. Winnicott, apresenta como uma de suas principais contribuiçóes a ênfase dada à influência do ambiente sobre a saúde emocional do bebê. Considera-se que o primeiro ambiente do bebê é a mãe, não existindo, inicialmente, um indivíduo e sim uma unidade ambiente-indivíduo (Winnicott, 1952/2000b).

Psic. Clin., Rio de Janeiro, vol. 25, N.I, P. 89- ioo, 2013 
Nesse sentido, o bebê só pode se tornar, gradualmente, um indivíduo a partir dos cuidados maternos que recebe. No entanto, o ambiente não pode ser totalmente responsabilizado pela saúde mental do bebê, pois, segundo Winnicott (1963/1993c), a base do desenvolvimento emocional envolve também os processos de maturação, que são tendências herdadas, cabendo ao ambiente fornecer as condiçóes necessárias para que tais processos se realizem.

As condiçóes ambientais, quando suficientemente boas, provêm ao bebê os cuidados que lhe são necessários, contribuindo assim para sua adaptação ativa. Desse modo, a psique origina-se dentro de um setting ${ }^{1}$, no qual a criança tem a possibilidade de, gradativamente, criar um ambiente pessoal, que mais tarde se transformará em algo suficientemente semelhante ao ambiente de sua percepção (Winnicott, 1952/2000c).

Sendo assim, nos primórdios das relaçốes objetais, a mãe deve adaptar-se às necessidades do bebê, que demandam respostas adequadas. $\mathrm{O}$ ambiente deve, entấo, propiciar a apresentação do objeto criado pelo bebê, isto é, no momento em que o bebê desenvolve a expectativa que se origina de uma necessidade, a mãe adaptada a ele apresenta um objeto ou um manejo corporal que satisfaça tal necessidade (Winnicott, 1963/1993c).

A mãe suficientemente boa deve então, no início, adaptar-se completamente às necessidades do bebê, oferecendo a ele a ilusão de que existe uma realidade externa correspondente à sua própria capacidade criativa. À medida que o tempo passa e a capacidade do bebê em lidar com experiências de frustração aumenta, a adaptaçáo materna deve diminuir gradativamente, de modo a tornar possível a vivência da desilusão, que permite ao bebê o reconhecimento gradual da realidade externa e a diferenciação desta da realidade interna (Winnicott, 1951/2000a).

Todavia, existe um estado intermediário entre a incapacidade do bebê de reconhecer a realidade e sua crescente capacidade de reconhecê-la, sem tentar localizá-la dentro ou fora de seu mundo, o que corresponde à terceira área ou área transicional. Esta área, incontestada quanto ao seu pertencimento à realidade interna ou externa, constitui-se na maior parte da vivência do bebê e nas experiências no campo da arte, da religiáo e da imaginaçáo do adulto, pois é neste espaço que se encontra a capacidade para criar de forma espontânea (Winnicott, 1951/2000a).

Tal área intermediária é relevante para que o bebê possa iniciar seu relacionamento com o mundo, o que só é possível quando houve uma maternagem suficientemente boa na fase crítica primitiva (Winnicott, 1951/2000a). No entanto, quando o ambiente não se adaptou às necessidades do bebê há o risco do surgimento de uma organização defensiva denominada de falso self.

Psic. Clin., Rio de Janeiro, vol. 25, N.I, P. 89 - IOO, 2013 
A constituição do falso self visa a preservar a continuidade do ser no self verdadeiro ameaçado, tratando-se de uma estratégia de sobrevivência fundamentada na resignação. Apesar de haver um grau de funcionamento falso self na normalidade, correspondente à atitude social, em casos extremos esse tipo de organização defensiva pode ocasionar diminuição da capacidade simbólica, pobreza na vida cultural, bem como sentimentos crescentes de futilidade e desespero por parte do indivíduo (Winnicott, 1959/1993a).

Portanto, a existência humana decorre da continuidade do ser, por meio dos processos de amadurecimento, assegurados não pelo indivíduo por si só, a partir de seu potencial inato, mas por um ambiente facilitador, que lhe dê a chance de um desenvolvimento saudável. Dessa forma, o amadurecimento emocional consiste na aquisição gradual da capacidade do indivíduo de ser si mesmo, para que possa existir de maneira criativa e perceber sentido na vida.

\section{As consultas terapêuticas}

As consultas terapêuticas representam uma nova possibilidade de avaliação, intervenção e ajuda psicológica norteada pela escuta, prática e flexibilidade clínica que advêm da teoria do amadurecimento humano. Embasadas nas necessidades do selfe de suas efetivações, que, segundo a clínica winnicottiana, exigem a presença de outro ser humano para se cumprirem, são conduzidas no sentido de se estabelecer uma comunicação significativa, ou seja, concentram-se na obtenção e manejo dos elementos vitais que possam ajudar o paciente na elaboração de um sofrimento ou dificuldade (Winnicott, 1965/1994b; Lescovar, 2004).

Nesse sentido, tal trabalho terapêutico tem como maior finalidade o fornecimento de sustentação emocional que permita a retomada da continuidade de ser da pessoa em tratamento, uma vez que, de acordo com Winnicott (1963/1993c), a provisão ambiental adequada facilita o processo interno de amadurecimento.

Garcia (2005) destaca que, no trabalho em consultas terapêuticas, o psicoterapeuta encontra-se na posiçấo de objeto subjetivo, ainda não percebido no mundo real, mas imaginado, o que permite que a criança possa confiar que será compreendida e, entáo, possa comunicar-se em nível profundo com ele. Quando um clima de confiança e a comunicação emocional são conquistados, a criança passa a exprimir criativamente suas fantasias, sua problemática e seus sonhos, enquanto o terapeuta, ao receber essas comunicaçóes, as reenvia ao paciente de maneira igualmente criativa, visando à possibilidade do acontecimento de uma mudança que leve a criança a retomar seu processo de amadurecimento pessoal (Lins \& Luz, 1998).

Psic. Clin., Rio de Janeiro, vol. 25, N.I, P. 89- ioo, 2013 
Lescovar (2004), com base nas ideias winnicottianas, afirma que à medida que o paciente começa a se sentir compreendido em seu sofrimento, as consultas passam a constituir uma espécie de jogo e interação em que os participantes estabelecem um diálogo por meio do brincar mútuo. Nesse contexto, Winnicott (1971/1975) ressalta que as consultas terapêuticas se produzem por meio da sobreposição das áreas lúdicas do paciente e do terapeuta, de modo que, se o terapeuta não consegue brincar, não está ajustado ao trabalho, e se o paciente não é capaz de brincar, algo precisa ser feito para possibilitar-lhe tal ação.

É somente por meio do brincar que o paciente tem a possibilidade de ser criativo e fazer uso de sua personalidade integral. Dessa forma, por meio da brincadeira, o paciente leva para a sessão elementos de experiências oriundas da realidade socialmente sustentada e os usa como elementos de enriquecimento e transformação no campo transicional. Dessa maneira, a sessão se torna um espaço potencial, que não é possível localizar no mundo interno ou externo, pois está entre eles, com potencial de criar ou recriar a transicionalidade infantil (Winnicott, 1971/1975).

As consultas terapêuticas se constituem em um espaço de desfrute, um espaço lúdico, partilhado por analista e paciente, que, segundo Franco (2003), invade o mundo interno de ambos sem que se tenha uma consciência plena do que ocorre. Esta vivência da sessão pensada próxima ao brincar promove o encontro do outro e de si mesmo, do self verdadeiro.

Um instrumento facilitador das consultas terapêuticas é o jogo dos rabiscos, criado por Winnicott como uma forma de comunicar-se com a criança por meio do brincar (Winnicott, 1965/1994b; Abram, 1986). Abadi (2002) ressalta que, para a clínica winnicottiana, o brincar abre caminho para os impulsos criativos, facilitando a comunicação consigo mesmo e com os outros, de modo que, nesse contexto, a interpretação no jogo dos rabiscos se constitui em um objeto criado e encontrado ao mesmo tempo, de caráter flexível e aberto, deixando espaço para a contribuição do paciente.

Com base em tais consideraçóes acerca do desenvolvimento emocional humano e das possibilidades de tratamento por meio das consultas terapêuticas, este trabalho apresenta o caso clínico de uma menina de oito anos atendida na clínica-escola de uma universidade pública.

\section{Jasmim e seu florescer}

A mãe de Jasmim (nome fictício) procurou atendimento psicológico para a filha referindo, em entrevista inicial, que, nos últimos meses, a criança vinha

Psic. Clin., Rio de Janeiro, vol. 25, N.I, P. 89 - IOO, 2013 
apresentando humor deprimido, com crises de choro sem motivos aparentes e temperamento difícil, com nervosismo intenso quando era contrariada. A menina reclamava constantemente de dor no peito, de tristeza intensa e de não sentir vontade de se levantar da cama.

Jasmim tem oito anos de idade, cursa o Ensino Fundamental, mora apenas com a mãe, pois seus pais se separaram após seu nascimento e suas duas irmãs mais velhas são casadas.

$\mathrm{Na}$ primeira sessão Jasmim verbalizou, de maneira muito intelectual, suas queixas: "Às vezes, fico triste, nervosa, sem nem ter motivo. Eu mesma não sei o porquê fico assim. Tá tudo bem e de repente eu já sinto nervoso, fico brava, falo nervoso com as pessoas. Outras vezes, eu fico cansada, mesmo sem nem ter feito nada. É assim, sem vontade de fazer nada". Jasmim apresentou dificuldade em brincar espontaneamente, recusando-se diante da proposta da analista: "Ai, hoje eu não quero fazer nada assim, sabe? Não quero brincar". Nos últimos minutos da sessão inicial, aceitou realizar o Jogo dos Rabiscos, que, de acordo com Winnicott (1965/1994b), conforme já mencionado anteriormente, consiste em um elemento facilitador das consultas terapêuticas.

O primeiro rabisco foi feito pela analista e Jasmim o transformou em uma blusa: "Pronto, uma blusa de zíper". Posteriormente, realizou um rabisco que sugeria um coraçáo, demonstrando novamente pouca espontaneidade e certa concretude. A analista transformou o rabisco em um cachorro, dizendo que, apesar de ser quase um coração, pois faltava apenas fechar o traçado, poderia ser também um cachorrinho. Jasmim sorriu e disse que poderiam dar-lhe o nome de Snoopy, mesmo nome de seu cachorrinho, o qual fora dado a outra pessoa pelo pai. Referiu que ficou triste quando isso aconteceu, pois seu pai o fez sem avisá-la, porém disse que depois entendeu o ocorrido ao saber que havia sido dado a uma criança e segundo ela: "Criança que dá mais atenção, que brinca mais, né? Adulto nem liga muito". Jasmim parece comunicar aqui sua ambivalência entre ser criança e ser adulta, ao dizer, inicialmente, o quanto tal fato a havia deixado triste e, posteriormente, que foi capaz de entender e não se importar tanto, já que "adulto nem liga muito". Além disso, pôde expressar a falta de adultos/pais que se importem com suas necessidades infantis, exigindo-se a tal ponto que deve entender a atitude paterna sem questionar e aceitá-la, talvez por receio de perder o seu amor; além disso, ela precisa negar o fato de ser criança, com objetivos defensivos.

$\mathrm{Na}$ sequência, o rabisco da terapeuta foi transformado em, segundo a paciente: "um seis bem gordinho". É importante assinalar que a mãe de Jasmim referiu como uma de suas queixas adicionais o fato de a criança comer muito e estar engordando consideravelmente. Depois realizou um rabisco que sugeria uma es-

Psic. Clin., Rio de Janeiro, vol. 25, N.I, P. 89 - ioo, 2013 
trela, faltando-lhe apenas um fechamento: "E pode fazer um rabinho aqui assim. Pra ficar uma estrela cadente". Jasmim disse que se visualizasse uma estrela cadente e pudesse fazer um pedido, pediria para não ficar mais tão nervosa. Esta fala da criança pode indicar um pedido de ajuda, uma vez que, segundo Winnicott (1971/1984), a primeira sessão apresenta um caráter peculiar propiciador deste tipo de comunicação, pois o paciente, geralmente, espera encontrar na comunicaçáo com o terapeuta o objeto necessitado para a superação de sua dificuldade e, consequentemente, a retomada de seu processo de amadurecimento.

Produziu-se um rabisco que Jasmim transformou em um mar com ondas e peixinhos, os quais, segundo ela, estavam com medo das ondas. Referiu também que um dos peixes estava gordinho e "comiláo". Neste desenho, a criança pareceu comunicar a vivência de um conflito que ainda não consegue nomear ou localizar, ressaltando que havia uma diferença considerável entre ela e os outros.

$\mathrm{O}$ rabisco seguinte de Jasmim pareceu à analista uma montanha. Jasmim disse: "Pensei em uma montanha com gelo caindo assim". A analista desenhou o gelo, como ela tinha sugerido, e um sol nascendo atrás da montanha. Jasmim disse que o sol era "pequenininho". A analista complementou que, mesmo pequeno, o sol estava presente e conseguindo, aos poucos, ir derretendo o gelo que estava caindo. Jasmim pediu, então, que a analista desenhasse um alpinista subindo a montanha. A criança desenhou um zíper na mochila do alpinista. A repetição de desenhos com zíper (blusa e mochila) pode indicar uma tentativa de proteger alguns de seus conteúdos. Ao ser questionada quanto ao sucesso do alpinista, Jasmim desenhou-o no topo da montanha: "Agora ele tá tranquilo, que ele conseguiu chegar". Tal fala pareceu demonstrar a esperança de cura da criança.

Por fim, disse que poderia desenhar uma casa. A analista perguntou como poderia ser a pessoa que habitava a casa de seu desenho, ao que Jasmim respondeu: "Ah, alguém bem sem graça. Vou fazer umas manchas aqui na parede". Complementou que apesar dos moradores terem algum cuidado com a casa, ela foi descascando e ficou com as paredes cheias de buracos. Este desenho permitiu a inferência de um ambiente insuficientemente bom, com falta de holding, uma vez que o cuidado despendido parece precário e confuso, não conseguindo impedir as "manchas" em seu mundo interno. Além disso, a parede remete à casca protetora "construída" pelo falso self, um revestimento precário, cheio de falhas, em uma tentativa de proteger o verdadeiro self.

Ao ser avisada quanto ao término da sessão, a criança perguntou se poderia levar um dos desenhos, escolhendo o do cachorrinho. Tal fato pode indicar a tentativa de uma integração entre alguma experiência de sua vida com a experiência da sessão, bem como revelar a sensação de acolhimento vivenciada pela criança durante $\mathrm{o}$ atendimento. 
Na sessão seguinte, Jasmim levou uma carta produzida por orientação de sua mãe, dizendo que seu pai estava namorando e isso a deixava triste. Ademais, ela se recusou a brincar, dizendo que não queria ter ido à sessão. Neste momento, parece que a criança se sente roubando um lugar que poderia ser da mãe, que utilizaria a sessão para conversar, além de demonstrar o quanto sua mãe também lhe tirava o espaço para sentir e expor suas próprias necessidades. A carta produzida pela máe trazia necessidades desta, incompatíveis com as necessidades da criança, denotando o quanto Jasmim se sentia pouco acolhida e pouco considerada pela figura materna.

Percebeu-se, a partir de então, a dificuldade que Jasmim apresentava na aquisição de sua autonomia, desconfiando de sua própria capacidade, dando relevância ao fato de se trabalhar sua autoconfiança ao longo dos atendimentos. Assim, o olhar dirigido para suas potencialidades permitiu maior segurança ao lidar com o ambiente e com seus próprios sentimentos, possibilitando diferenciá-los dos de sua máe.

As sessóes seguintes apontaram, cada vez mais claramente, para a confusão entre os sentimentos da criança e os da mãe, bem como para sua sobrecarga diante do lugar em que era colocada devido ao conflito dos pais, indicando a sensação de não ser vista por eles. Neste período, a mãe chegou a solicitar uma participação nas sessôes da criança, ao que foi sugerido que ela iniciasse seu próprio atendimento.

A mãe passou a ser atendida semanalmente na mesma clínica-escola, por outra terapeuta, e Jasmim pôde, entáo, apropriar-se do seu atendimento, passando a mostrar tranquilidade para realizar atividades lúdicas ("Hoje eu quero pintar com guache") e demonstrando maior disposição em ir para as sessóes ("Continuamos na próxima sessão, cenas do próximo capítulo"). Apesar disso, a criança ainda protegia alguns conteúdos, pois em suas atividades apareciam constantemente cercas, caixas e janelas fechadas, animais com caçadores apontando-lhes armas, entre outros. Segundo Winnicott (1986/1993d), o analista deve saber esperar, sem a ânsia de retirar o mal-estar do paciente, pois ele deseja ser aceito assim. Nesse sentido, aceitar a função do sofrimento é possibilitar o rumo de um viver criativo. Além disso, é essencial dar à criança um espaço onde possa se comunicar e ser compreendida, sem que se sinta invadida.

Com o estabelecimento de um clima de confiança, constância e previsibilidade, Jasmim pareceu, pouco a pouco, poder baixar as guardas defensivas (falso self) e desfrutar de um estado de relativo relaxamento e não integraçáo, comunicando-se a partir de seu self verdadeiro no espaço potencial entre ela e a analista. Em determinada sessão, Jasmim pintava uma boneca com guache, dizendo que a cor dos cabelos seria a mesma dos seus, que a roupa seria rosa, porque era a cor de que mais gostava, ou seja, demonstrando identificação. Posteriormente, resolveu pintar uma máscara em torno dos olhos da boneca e ao terminar disse: "Ixi, ficou muito estranho! Nossa, tá

Psic. Clin., Rio de JANeiro, vol. 25, N.I, P. 89 - IOO, 2013 
aterrorizante! Ai, póe isso pra lá!", aparentando a descoberta de uma imagem que ela criou, mas que ainda the parecia estranha. A máscara pode simbolizar o falso self, que não agrada mais Jasmim e a assusta, como se aquele conteúdo não fizesse mais parte dela, fosse-lhe estranho, mas precisasse ser visto para ser abandonado.

Nas sessōes seguintes emergiram questóes referentes às diferenciaçōes. Ora se identificando, ora se diferenciando de figuras importantes. Ora abordando seus aspectos negativos, ora conseguindo reconhecer seus aspectos positivos. Em alguns dos encontros, Jasmim passou a referir cansaço: "Ah, cansei. Já deu a hora, né?". Aparentemente, seu cansaço relacionava-se ao seu dinamismo interno, uma vez que sua dinâmica, para ser espontânea e criativa, aparentava demandar grande dedicação e energia.

Sua espontaneidade pessoal passou a surgir com maior intensidade nas sessões posteriores, permitindo emergir, inclusive, sua agressividade: "Ah, nem usamos seus brinquedos, né? Tem tantos aqui, que nem precisou". Porém a criança, em alguns momentos, passou a tentar brecar seus gestos espontâneos, parecendo achar feio tudo o que produzia de maneira mais livre. "Ah, o que tá acontecendo comigo? Meus desenhos táo ficando feios!", como se os visse pela primeira vez e também como se estivesse testando sua capacidade criativa, em um jogo de faz-desfaz.

Depois disso, iniciou-se um processo de valorização pessoal nas sessões, evidenciando indícios de idealização de si a fim de corroborar sua autoestima ("Gente, sou muito sortuda! Que lindo! Adorei esse vaso que eu fiz! Tô impressionada!"), supostamente com uma facilidade maior de demonstrar seus aspectos negativos, como competitividade, capacidade de burlar regras etc., apropriando-se de maneira pessoal daquilo que realizava. Este movimento pode sinalizar a experiência dos processos de ilusão-desilusão, em que a criança vivencia momentos de onipotência, de grandeza criativa e outros de falha, de frustração e até de insegurança (Winnicott, 1952/2000c).

Com a proximidade do encerramento dos atendimentos, devido ao período de férias da clínica-escola, Jasmim passou a tentar deixar sua marca nas sessôes e no setting. Na penúltima sessão, ela desenhou na lousa duas borboletas, reforçando os caminhos que percorreram e pedindo que o desenho fosse deixado na lousa. Assim, a proximidade do encerramento foi, necessariamente, bastante trabalhada com a criança, permitindo-se que ela pudesse sentir a ausência do outro não como desaparecimento, mas como frustração tolerável, com a confiança de que o contato ia ser restabelecido, denotando-se a presença de uma experiência suficientemente boa que pudesse permanecer viva em sua memória (Winnicott, 1964/1994a).

$\mathrm{Na}$ sessão de encerramento para as férias, Jasmim sugeriu que desenhassem. Iniciou o desenho de um palhaço e solicitou que a analista o terminasse.

Psic. Clin., Rio de Janeiro, vol. 25, N.I, P. 89 - IOO, 2013 
Em seguida, pintou. Ao terminar, contou que agora estava dormindo em seu próprio quarto, e que nele havia uma parede cheia de desenhos e adesivos, onde iria colar também aquele desenho. É relevante destacar que Jasmim sempre dormiu no quarto da mãe, não conseguindo ficar em seu próprio quarto. Neste momento ela parecia estar se sentindo mais à vontade em casa, em ter seu próprio espaço, o que pode indicar uma identificação com seus próprios aspectos (sua casa interna) que, aos poucos, foi descobrindo e construindo na relaçáo com a analista, a qual deseja manter por perto durante o período de afastamento. Além disso, esta sessão denotou o quanto foi importante o encontro com a analista, pois Jasmim pôde se lembrar do primeiro "jogo" realizado por ambas, mostrando o quanto havia guardado da experiência vivida e das possibilidades de retomada de seu desenvolvimento emocional (uma parede cheia de desenhos).

Posteriormente, a criança passou a se lembrar de como chegara ao atendimento, comparando as sessóes iniciais com as finais: "Eu não queria vir. Ficava preocupada com o que eu ia falar. Hoje eu gosto de vir. Às vezes, é sábado, aí eu durmo depois do almoço e acordo e olho que são três horas, aí eu grito com a minha mãe que a gente tá atrasada pra terapia, mas depois eu lembro que não é o dia”. Tal relato pareceu demonstrar que a criança passou a se apropriar e se responsabilizar pelo atendimento, por aquilo que é seu, buscando a continuidade de seu espaço na tentativa de preservar aquilo que lhe fazia sentido.

De um modo geral, Jasmim se mostrou uma criança mais segura, mais criativa, mais viva. A mãe referiu, na entrevista de encerramento para as férias, ter notado grande melhora quanto às queixas inicialmente apresentadas.

Após o período de férias, o atendimento foi retomado. Ao retornar, Jasmim revelou sua dificuldade em ficar sem as sessōes, entretanto relatou ter se sentido mais confiante quanto às suas atitudes. Sugeriu, então, que desenhassem um quadro com paisagens. Ao observar que a terapeuta desenhava flores grandes e coloridas, disse: "Também vou desenhar flores, mas as minhas ainda estão brotando...”.

\section{Consideraçóes finais}

Com este breve apanhado teórico e a apresentação do caso clínico, procurou-se abordar não apenas a modalidade de ajuda psicológica criada por Winnicott, as consultas terapêuticas, mas também, e principalmente, demonstrar a ampliação no modo de se realizar a clínica psicanalítica que tal modalidade

Psic. Clin., Rio de Janeiro, vol. 25, N.I, P. 89- ioo, 2013 
representa. Nesse sentido, é relevante salientar que o resultado satisfatório do atendimento psicológico de Jasmim foi favorecido pelo tempo, pelo espaço e pela relação humana propiciados pelas consultas terapêuticas.

Nesse sentido, o brincar na sessão analítica propiciou que a criança tivesse possibilidades de ser criativa, fazendo uso pessoal dos objetos por meio do gesto espontâneo. Jasmim pôde demonstrar elementos de sua experiência vivida até então e usá-los para enriquecer e transformar o campo analítico, dentro do espaço transicional, com reflexos em seu mundo interno. Dessa maneira, foi possível perceber a passagem entre mundo interno e externo, o potencial criativo, o encontro do outro e de si mesmo, a expressão do verdadeiro self presente no amadurecimento emocional.

Além disso, o jogo dos rabiscos se mostrou importante instrumento de comunicação com a criança, por meio do encontro com um objeto criado, tanto pelo paciente quanto pelo analista, que está ali, presente na dupla e que pode ser acessado da maneira como for possível a ambos.

Concluindo, este estudo teve como foco a valorização dos manejos clínicos e das vivências constitutivas do si mesmo da criança por meio do brincar compartilhado, buscando a comunicação emocional entre terapeuta e paciente como único meio de intervenção, bem como o destaque à reciprocidade entre a prática clínica e o modelo conceitual fundamentado na teoria do amadurecimento humano de Winnicott.

\section{Referências}

Abadi, S. (2002). Explorações: perder-se e achar-se no espaço potencial. Revista Brasileira de Psicanálise, 36(4), 807-816.

Abram, J. (1986). Ambiente. In: Abram, J. A linguagem de Winnicott: dicionário de palavras e expressóes utilizadas por Donald D. Winnicott (pp. 25-38). Rio de Janeiro: Revinter.

Franco, S. G. (2003). O brincar e a experiência analítica. Ágora: estudos em teoria psicanalítica, 6(1), 45-59.

Garcia, R. M. (2005). O uso da consulta terapêutica na clínica da tendência anti-social. $N a$ tureza Humana, 7(1), 209-234.

Lescovar, G. Z. (2004). As consultas terapêuticas e a psicanálise de D. W. Winnicott. Revista Estudos de Psicologia, 21(2), 43-61.

Lins, M. I. A. \& Luz, R. (1998). D. W. Winnicott: experiência clínica e experiência estética. Rio de Janeiro: Revinter.

Winnicott, D. W. (1975). O brincar: uma exposiçấo teórica. In: Winnicott, D. W. O brincar e a realidade (pp. 59-78). Rio de Janeiro: Imago. (Trabalho original publicado em 1971)

Psic. Clin., Rio de Janeiro, vol. 25, N.I, P. 89 - IOO, 2013 
Winnicott, D. W. (1984). Consultas terapêuticas em psiquiatria infantil. Rio de Janeiro: Imago. (Trabalho original publicado em 1971)

Winnicott, D. W. (1993a). Classificação: existe uma contribuição psicanalítica à classificação psiquiátrica? In: Winnicott, D. W. O ambiente e os processos de maturação: estudos sobre a teoria do desenvolvimento emocional (pp. 114-127). Porto Alegre: Artes Médicas. (Trabalho original publicado em 1959)

Winnicott, D. W. (1993b). A integração do ego no desenvolvimento da criança. In: Winnicott, D. W. O ambiente e os processos de maturação: estudos sobre a teoria do desenvolvimento emocional (pp. 55-61). Porto Alegre: Artes Médicas. (Trabalho original publicado em 1962)

Winnicott, D. W. (1993c). Dependência no cuidado do lactante, no cuidado da criança e na situação psicanalítica. In: Winnicott, D. W. O ambiente e os processos de maturaçâo: estudos sobre a teoria do desenvolvimento emocional (pp. 225-233). Porto Alegre: Artes Médicas. (Trabalho original publicado em 1963)

Winnicott, D. W. (1993d). Tudo começa em casa. São Paulo: Martins Fontes. (Trabalho original publicado em 1986)

Winnicott, D. W. (1994a). A importância do setting no encontro com a regressão na psicanálise. In: Winnicott, C., Sheperd, R. \& Davis, M. (org.). Exploraçóes psicanalíticas: D. W. Winnicott (pp. 77-81). Porto Alegre: Artmed. (Trabalho original publicado em 1964)

Winnicott, D. W. (1994b). O valor da consulta terapêutica. In: Winnicott, C., Sheperd, R. \& Davis, M. (org.). Exploraçôes psicanalíticas: D. W. Winnicott (pp. 244-248). Porto Alegre: Artmed. (Trabalho original publicado em 1965)

Winnicott, D. W. (2000a). Objetos transicionais e fenômenos transicionais. In: Winnicott, D. W. Da pediatria à psicanálise: obras escolbidas (pp. 316-331). Rio de Janeiro: Imago. (Trabalho original publicado em 1951)

Winnicott, D. W. (2000b). Ansiedade associada à insegurança. In: Winnicott, D. W. Da pediatria à psicanálise: obras escolhidas (pp. 163-167). Rio de Janeiro: Imago. (Trabalho original publicado em 1952)

Winnicott, D. W. (2000c). Psicose e cuidados maternos. In: Winnicott, D. W. Da pediatria à psicanálise: obras escolhidas (pp. 305-315). Rio de Janeiro: Imago. (Trabalho original publicado em 1952)

\section{Notas}

${ }^{1}$ Setting entendido como um ambiente de constância, confiabilidade e previsibilidade.

Recebido em 11 de agosto de 2012 Aceito para publicação em 25 de fevereiro de 2013

Psic. Clin., Rio de JANeiro, vol. 25, N.I, P. 89 - IOO, 2013 